\title{
Atitudes em Relação ao HIV/aids nos Alunos das Escolas Secundárias de Moçambique: Um Estudo Comparativo Entre as Províncias de Maputo e Niassa
}

\author{
Benvindo Felismino Samuel Maloa ${ }^{*, a, b}$ \& Marcos Emanoel Pereira ${ }^{a}$ \\ ${ }^{a}$ Universidade Federal da Bahia, Salvador, Brasil \& ${ }^{\text {b} U n i v e r s i d a d e ~ P e d a g o ́ g i c a ~ d e ~ M o c ̧ a m b i q u e, ~ M a p u t o, ~ M o c ̧ a m b i q u e ~}$
}

\begin{abstract}
RESUMO
O objetivo do estudo foi analisar as atitudes dos alunos das províncias de Maputo e Niassa frente ao vírus HIV-aids, nas escolas secundárias onde o programa Geração Biz está sendo implementado e em escolas onde não está sendo implementado. Participaram 391 alunos, sendo utilizado o Questionário Sociodemográfico e a Escala de Atitudes Frente ao HIV-aids (EAFAIDS). Os alunos de Maputo apresentaram valores mais positivos em todas as dimensões na EAFAIDS. Os alunos cujas escolas estão implementando o programa obtiveram atitudes mais positivas apenas na dimensão da relação com os soropositivos na EAFAIDS. Conclui-se que as ações de prevenção devem ter em conta as diferenças socioculturais do país.
\end{abstract}

Palavras-chave: HIV-aids; educação para a saúde; atitudes sociais.

\section{ABSTRACT \\ Attitudes toward HIV/aids in students at secondary schools in Mozambique: A comparative study between Maputo and Niassa provinces}

\begin{abstract}
The aim of this study was to analyze students' attitudes from the provinces of Maputo and Niassa regarding HIV-aids in the secondary schools where the Generation Biz program is being implemented and in schools where it is not implemented. 391 students participated, using the Socio-demographic Questionnaire and the Scale of Attitudes towards HIV-aids (EAFAIDS). Students in Maputo showed more positive results in all scopes of EAFAIDS. Students whose schools are implementing the program had more positive attitudes only in relation to the size of the HIV positive people in EAFAIDS. It is concluded that prevention efforts must take into account the country's socio-cultural differences.
\end{abstract}

Keywords: HIV-aids; health education; social attitudes.

Originário de um mesmo vetor - o vírus HIV é aplicável aos membros de uma mesma espécie, a humana - a aids não exerce o mesmo impacto em todas as partes do mundo. Se, em alguns países, suas consequências negativas foram assimiladas e estão relativamente controladas, em outros, os efeitos da epidemia ainda são devastadores. Comparar os números relativos à África Subsaariana, a região mais afetada no mundo, com cerca de 22,5 milhões de adultos e crianças portadores do HIV, com o que se sabe sobre a América Latina, na qual se estima que cerca de 1,6 milhões de adultos e crianças sejam soropositivos, é suficiente para compreender o que significa a aids na
África Subsaariana e o desafio que ela representa para o desenvolvimento e o bem-estar da população dos países localizados nessa região do mundo (Organização das Nações Unidas para o Combate a aids, 2008).

Em Moçambique, um dos países aí localizados, a taxa de prevalência atual do HIV-aids é de 11,5\%, extraordinariamente alta quando comparada com a do Brasil, onde se estima a prevalência em cerca de $0,5 \%$ da população (Ministério da Saúde, 2010; Programa das Nações Unidas Para o Desenvolvimento, 2010). Quanto maior o número de portadores, mais difícil se torna para as agências de governo manter em estoque e distribuir, de forma sistemática, os antiretrovirais

* Endereço para correspondência: Benvindo Felismino Samuel Maloa - bfsmaloa@yahoo.com.br. 
para todos que deles necessitam, o que aumenta consideravelmente a taxa de mortalidade e, em última instância, impede que os soropositivos possam ter padrões razoáveis de vida, uma meta relativamente simples de ser alcançada hoje em dia, desde que determinadas condições sejam satisfeitas.

Dada a magnitude do desafio que a aids representa para alguns países africanos, o governo de Moçambique criou o Conselho Nacional de Combate ao HIV-aids, órgão ao qual se atribui a responsabilidade de coordenar os vários programas de combate à epidemia. Um desses programas, implementado em algumas escolas secundárias públicas, o programa Geração Biz, procura combater os efeitos negativos e a visão preconceituosa contra as pessoas vivendo com vírus HIV. Para tal, adota uma estratégia de ação que se coaduna com a tese de que a oferta de informações deve ser priorizada, o que se imagina ser capaz de contribuir para o desenvolvimento de ações mais propositivas de prevenção da propagação da epidemia e de promover atitudes e comportamentos mais positivos em relação às pessoas que vivem com o HIV (Conselho Nacional de Combate ao HIV-SIDA, 2010). Em que pese a existência de vários programas desenvolvidos pelo governo e por organizações não governamentais, o número de infectados continua a crescer.

$\mathrm{O}$ estudo que deu origem ao presente artigo foi conduzido com o objetivo de avaliar o impacto do programa Geração Biz em duas províncias moçambicanas, Maputo e Niassa. Conforme assinala Matsinhe (2006), pouco se sabe a respeito das atitudes das pessoas em relação aos infectados, o que torna necessário a avaliação do impacto dos diversos programas de prevenção. Em Moçambique, as doenças e os infortúnios geralmente são atribuídos a causas não naturais, sendo usualmente explicados mediante ao apelo a entidades espirituais, sobrenaturais e mágicas. Se as estratégias de intervenção desconsiderarem as especificidades de cada zona geográfica e cultural, as diretrizes globais adotadas pelos programas podem se tornar menos efetivas face aos múltiplos sistemas de crenças e estereótipos acerca do HIV-aids compartilhados pelos diversos grupos sociais. Mesmo em Maputo, a mais cosmopolita cidade do país, não é incomum a publicação de anúncios de curandeiros, em jornais de grande circulação, nos quais se afirma, com todas as letras, que a cura da aids é possível mediante a intervenção de entidades não-naturais.
$\mathrm{Na}$ ausência de um sistema confiável de informações sobre o HIV-aids, pode-se detectar certa dificuldade em recensear as pesquisas conduzidas sobre o assunto, pois falta a Moçambique um sistema confiável de dados. Um dos poucos estudos amplamente divulgado é a tese de doutorado "Tabula Rasa: dinâmica da resposta moçambicana contra o HIV-aids", na qual são analisadas as respostas do governo de Moçambique frente à pandemia e se conclui que as estratégias falham por desconsiderarem as diferentes características culturais das várias regiões do país (Matsinhe, 2006).

Nesse contexto, no qual os números de contaminação não parecem recrudescer e as fontes de informação sobre o assunto parecem pouco confiáveis, podese esperar que os preconceitos contra os portadores do HIV se manifestem com renovado vigor. Um preconceito pode ser entendido como uma atitude negativa a respeito de um determinado grupo ou de uma pessoa que se supõe pertencer àquele grupo (Pereira, 2002). Provavelmente, a expressão das diversas formas de preconceito contra o portador do HIV-aids se originou nos alvores da epidemia, ainda na década de 1980 , quando se constatou que os homens que faziam sexo com outros homens eram os mais afetados, donde se derivou a conclusão de que o vírus afetava apenas esse grupo de pessoas. Representou-se a aids como uma doença destinada a punir aqueles que apresentam comportamentos desviantes, ou seja, como algo que afetava exclusivamente as pessoas que pertenciam a determinados grupos de risco. Esse sistema de crenças a respeito dos portadores do HIV-aids intensificou o potencial de sofrimento dos infectados, pois, além de enfrentarem as consequências e complicações inerentes aos efeitos do vírus e das várias doenças oportunistas, em uma época em que os antiretrovirais eram pouco desenvolvidos, os portadores também passaram a enfrentar o preconceito e, em consequência, as distintas formas de exclusão social e discriminação.

Se a partir de meados dos anos oitenta do século passado se passa a acreditar que qualquer um, independentemente da orientação sexual, idade ou gênero, pode ser infectado pelo HIV, esse reconhecimento não resultou numa mudança significativa em relação ao potencial de estigmatização dos portadores do HIV, que continuaram a serem vistos como responsáveis pelo estado em que se encontravam e, como tal, continuaram a ser objeto de discriminação (Faria, 2007). Esse é um fenômeno recorrente em muitos países, 
mesmo naqueles que alcançaram notável sucesso no enfrentamento da epidemia. No Brasil, por exemplo, Garbin et al. (2009) realizaram um estudo com o objetivo de verificar a percepção dos portadores do HIV de um centro de referência para o tratamento de DSTHIV-aids, com relação à qualidade do atendimento prestada pelos profissionais de saúde, e concluíram que a maioria dos soropositivos já tinha vivenciado uma situação de discriminação fora das unidades específicas de tratamento dos soropositivos e acreditavam que apenas nas unidades especificas para o tratamento dos soropositivos eram bem tratados.

Já desde há muito tempo, psicólogos têm se interessado em estudar as atitudes com o intuito de perceber se elas podem ser ou não preditores de comportamentos. As pesquisas não são consistentes, pois se algumas evidenciam alguma congruência entre as ações e as atitudes, em outras os resultados apontam para uma direção inversa.

\section{Programa Geração Biz}

A Conferencia Internacional sobre a População e Desenvolvimento, realizada na cidade de Cairo em 1994, exerceu um importante papel na concepção e implementação do programa Geração Biz. Nessa conferência, foram identificadas algumas prioridades para impulsionar o desenvolvimento dos países subdesenvolvidos, e uma delas foi a garantia de acesso aos serviços de saúde sexual e reprodutiva, em particular com o desenvolvimento de programas de prevenção à infecção pelo HIV-aids voltados para a população de adolescentes e jovens adultos (Ministério da Educação e Cultura, 2010).

Institucionalmente, o programa encontra-se subordinado a três órgãos públicos, o Ministério da Saúde, responsável pela testagem voluntária do HIV, bem como pelo tratamento de outras infecções sexualmente transmissíveis, o Ministério da Educação e Cultura, cuja função prioritária é o desenvolvimento de atividades destinadas a prevenir a difusão do HIV-aids entre os adolescentes e jovens que mantêm vínculos com o sistema de ensino formal e, por último, o Ministério da Juventude e Desportos, que se encarrega de desenvolver atividades cujo alcance se amplia no sentido de atingir uma população de adolescentes e jovens que se encontra fora do sistema de educação formal.

Financiado pelo Fundo das Nações Unidas para a População (UNFPA), o programa foi implantado ini- cialmente em 1999 nas províncias de Maputo e Zambézia; em 2002, as atividades se ampliaram e alcançaram as províncias de Gaza e Tete; em 2003, expandiu-se para a província de Cabo Delgado até, finalmente, ser implementado, no ano de 2005 , na província de Niassa.

A principal meta do programa continua sendo a de melhorar a saúde sexual e reprodutiva de adolescentes, incluindo a redução da incidência da gravidez precoce, das doenças sexualmente transmissíveis e do HIV-aids dentro desse grupo populacional. As estratégias de intervenção dependem da formação de ativistas, ou seja, de educadores que se dediquem a atividades como a distribuição de preservativos masculinos e de panfletos educativos sobre as doenças sexualmente transmissíveis e sobre o HIV-aids, a organização de sessões de exibição de vídeos que retratem a aids e o patrocínio de debates sobre o tema. Espera-se que tais ações ofereçam aos jovens os conhecimentos e habilidades para lidar com o HIV-aids, além de proporcionarem facilidades de acesso a serviços de qualidade (Ministério da Educação e Cultura, 2010). Adicionalmente, o programa também pretende fortalecer a oferta nacional de prestação de serviços curativos a adolescentes e jovens e, consequentemente, mitigar os impactos negativos do HIV-aids.

\section{Buscando a inspiração em práticas de sucesso}

Se, nos anos 1980, acreditava-se que a aids era uma doença quer atingia exclusivamente os homossexuais (Faria, 2007), hoje essa crença foi abalada, passando-se a acreditar que qualquer pessoa pode ficar infectada pelo vírus HIV. As ações deixaram de ser dirigidas aos grupos de risco e passaram a ostentar como alvo os mais diversos grupos sociais. A massificação da testagem voluntária permitiu que um número muito grande de pessoas tivesse acesso aos exames sorológicos. Em 2004, por exemplo, 28\% da população sexualmente ativa brasileira já haviam realizado o teste anti HIV pelo menos uma vez na vida (Ministério da Saúde, 2005). A política de acesso universal aos antiretrovirais, patrocinada pelo Serviço Único de Saúde (SUS) a partir de 1996, sob os auspícios da lei 9.313 (Granjeiro, Teixera, Bastos \& Teixera, 2006; Ministério da Saúde, 2005), bem como a disponibilização do preservativo masculino de forma gratuita nos serviços de saúde do Estado exerceram um importante efeito na redução das taxas de infeção pelo HIV. Ações dessa natureza tornaram o Brasil um dos países 
mais bem-sucedidos na prevenção e tratamento das pessoas com o HIV-aids. As taxas de prevalência do HIV, na população de 15 a 49 anos, são inferiores a $1 \%(0,65 \%)$, embora, em alguns grupos - a exemplo dos homens que fazem sexo com outros homens, das trabalhadoras de sexo e dos usuários de drogas injetáveis -, essas taxas sejam significativamente mais altas (Brazilian Ministry of Health, 2010). A taxa de prevalência do HIV pode ser considerada estacionária, pois, em 2001, era de 0,6\%, e, no ano seguinte, alcançou cerca de $0,5 \%$ da população, valor que se mantém nos mesmos patamares até a atualidade (Programa das Nações Unidas para o Desenvolvimento, 2008). Segundo o Ministério da Saúde do Brasil (Brazilian Ministry of Health, 2010), o sucesso de campanhas de prevenção e tratamento da aids, no Brasil, deve ser atribuído ao trabalho conjunto e a uma estreita colaboração entre o Estado, as organizações não governamentais e a sociedade civil.

Outro caso bem-sucedido de combate à aids, e o único, até então, entre os países africanos, é o de Uganda, país também situado na África Subsaariana. Observou-se, nesse caso, na população situada numa faixa etária compreendida entre os 15 e os 49 anos de idade, uma brutal redução da prevalência, ao se considerar a redução dos valores registrados em 1992, de cerca de 18\%, para cerca de 6,7\% em 2005 (Bukusula, Kikafunda \& Whitehead, 2007). A tendência parece ser decrescente, pois, segundo o Programa das Nações Unidas para o Desenvolvimento (2008), a prevalência nacional entre os habitantes da mesma faixa etária foi de 5,4\% em 2007. Atribui-se esse sucesso à implementação de ações como a massificação de programas de educação para a saúde, o aconselhamento, a testagem voluntária, o incentivo para a abstinência dos jovens que não iniciaram a vida sexual e, particularmente, a implementação de programas destinados a combater a insegurança alimentar (Bukusula, Kikafunda \& Whitehead, 2007; Mason, 2007).

\section{As atitudes}

Uma atitude corresponde a uma representação mental que condensa a avaliação de um objeto atitudinal (Leyens \& Yzerbyt, 2004) e pode ser caracterizada por predisposições para agir de uma maneira favorável ou não em relação a determinados fenômenos naturais ou sociais. A atitude, nesse sentido, pode ser positiva, negativa ou neutra, sendo um predicativo eminentemente avaliativo (Eagly \& Chaiken, 1998).
No plano pragmático, o conceito encontra relevância na psicologia social, por se acreditar que, a partir dos conhecimentos acerca das atitudes, é possível estabelecer algum tipo de predição a respeito do comportamento das pessoas que expressam a sua avaliação sobre um determinado objeto atitudinal. Concebe-se, portanto, dado o potencial preditivo das atitudes, que uma boa estratégia para modificar um padrão de comportamento ou ação pode residir no desenvolvimento de mudanças nas atitudes.

As atitudes se formam e sofrem mudanças ao longo do processo de socialização. O princípio geral mais aceito a respeito da formação e da mudança de atitudes se assenta no entendimento de que elas se formam ou são modificadas pela oferta ou aquisição de novas informações que podem modificar as crenças sobre os atributos dos objetos atitudinais. A família, a instância primária de socialização, desempenha um papel decisivo na formação das crenças e atitudes (Aparecido, Buchala, Paiva, Oliveira, Stall \& Norman, 2002; Kruger, 1986). O grupo de coetâneos, formado basicamente por indivíduos da mesma idade, constitui outro meio importante de influência, em especial na adolescência. $\mathrm{O}$ adolescente tende a se comportar como o seu ídolo, que pode ser um artista, um professor ou até mesmo outro adolescente mais velho.

Ademais, é importante destacar a importância dos meios de comunicação de massa, como o rádio, a televisão e, atualmente, a Internet, agentes que contribuem para a formação das atitudes. No caso de Moçambique, por exemplo, é notória a influência das telenovelas brasileiras, principalmente na população feminina. O efeito dessas peças de ficção sobre a população feminina é marcante, sendo possível notar a influência, por exemplo, dos trajes das personagens na vestimenta das mulheres moçambicanas, em especial nas que moram nas cidades maiores. Essa mudança nos estilos de vestuário evidencia o impacto dos meios de comunicação de massa na formação e na mudança das atitudes e comportamentos. (Leyens \& Yzerbyt, 2004).

A formulação teórica mais clássica no estudo das atitudes sugere que elas são compostas por três componentes, o cognitivo, o afetivo e o comportamental (Leyens \& Yzerbyt, 2004; Rodrigues, 2007). O componente cognitivo é constituído por um conjunto de conhecimentos e crenças sobre determinados objetos. Durante o processo de socialização, o aprendiz passa a ter contatos com várias formas de explicar os fenôme- 
nos naturais e sociais, desenvolvendo, em consequência, crenças sobre a natureza desses fenômenos (Fonseca, Gouveia \& Gouveia, 2007).

Nos países subdesenvolvidos, a exemplo de Moçambique - onde, segundo o Instituto Nacional de Estatística (1997), mais de 60,5\% da população não sabe ler e escrever -, a influência da escola pode não ser tão marcante quanto em outros contextos. A comparação dos índices de escolarização de homens e mulheres suscita a interpretação de que a população feminina é menos alfabetizada em relação à masculina, $74,1 \%$ contra $44,6 \%$, respectivamente (Instituto Nacional de Estatística, 1997). Essa alta taxa de analfabetismo, particularmente entre as mulheres, pode sugerir que talvez a escola exerça uma influência mais modesta do que outras fontes de influência, a exemplo da religião, da família e dos ensinamentos tradicionais dos moradores mais velhos da comunidade, na formação e consolidação das atitudes. Essa situação pode gerar um debate considerável acerca da efetividade da ação de programas cuja ação tem por foco o ambiente escolar, a exemplo do programa Geração Biz.

Se, no ambiente escolar, por exemplo, o uso do preservativo é considerado fundamental para evitar a infecção pelo HIV, no contexto residencial, a pessoa pode estar sujeita a outras fontes de influência, como, por exemplo, de um curandeiro que assegura que a infecção poderia ter sido evitada se as pessoas tivesse andado com amuletos. A crença de que os curandeiros têm maior poder de cura e estão habilitados a prevenir e tratar doenças e outros infortúnios parece ser central nos países da África Subsaariana. Na África do Sul, por exemplo, estima-se que, ao adoecer, cerca de $80 \%$ da população recorre inicialmente aos serviços de um curandeiro, antes de procurar os serviços médicos convencionais (Donnelly, 2004).

Sobre o componente afetivo, pode-se afirmar que, na base das nossas crenças e dos nossos conhecimentos, estão presentes sentimentos e afetos em relação aos objetos atitudinais. Essa avaliação pode ser positiva ou não. Se a solidariedade para com os soropositivos é vista como benéfica, a probabilidade do desenvolvimento de atitudes positivas para com eles é bem mais alta; se, no entanto, a solidariedade não é percebida como benéfica, podem-se desenvolver sentimentos negativos sobre os portadores, e isso facilmente pode levar ao surgimento de atitudes preconceituosas ou ações de discriminação frente aos soropositivos.
É impossível referir-se às atitudes sem estabelecer alguma relação com o comportamento. As ações e reações dos indivíduos dependem, em parte, de como eles avaliam as pessoas e os objetos sociais e não sociais. Essa suposição de que as atitudes são capazes de predizer o comportamento foi um dos principais determinantes do interesse dos psicólogos sociais pelo estudo das atitudes. Esse, no entanto, não é um assunto inteiramente resolvido, dada a diversidade de opiniões a respeito da natureza das relações entre as atitudes e o comportamento. O ponto de vista aqui defendido se coaduna com o daqueles que, embora não considerem existir uma correspondência perfeita entre atitudes e comportamentos, consideram que o conhecimento da atitude de uma pessoa permite, com uma razoável probabilidade de sucesso, prever o comportamento futuro. Assim, espera-se que uma atitude favorável ao uso do preservativo se encontre associada não apenas à intenção de utilizá-lo, como também à sua utilização efetiva (Camargo \& Botelho 2007). Desafortunadamente, em muitas regiões de Moçambique, ainda prevalece uma atitude bastante negativa em relação ao uso do preservativo. Essa atitude se sustenta em crenças estereotipadas, a exemplo de que "fazer sexo com preservativo é deitar fora filhos", "fazer sexo com preservativo é um perigo, porque ele pode-se colocar no útero e impedir a procriação futura", "fazer sexo com preservativo é comer banana com casca" ou "fazer sexo com preservativo é como tomar banho com capa". Presume-se que a probabilidade de que pessoas com atitudes semelhantes venham a utilizar o preservativo como meio de proteção contra o HIV-aids é relativamente baixa, particularmente se for estabelecida uma comparação em relação àquelas que veem o preservativo como um meio eficaz para a proteção contra as doenças sexualmente transmissíveis.

\section{Objetivo e Hipóteses}

Devido às diferenças no nível de desenvolvimento econômico, social e cultural das províncias de Maputo e Niassa, o primeiro objetivo do presente estudo é identificar se tais diferenças se refletem nas atitudes dos estudantes das escolas secundárias moçambicanas em relação ao HIV-aids, esperando-se que as atitudes sejam mais positivas na província de Maputo, uma vez que aí se identifica um maior índice de escolarização, uma maior proporção de habitantes nas zonas urbanas, um maior índice de acesso aos meios de comunicação de massa e, consequentemente, uma visão 
de mundo mais cosmopolita diferentemente de Niassa, onde a maior parte da população mora no meio rural, regista-se uma fraca escolarização assim como o acesso aos meios de comunicação de massa. Ademais, considerando que os objetivos do programa Geração Biz contemplam a promoção da solidariedade e o respeito pelos portadores de HIV-aids, espera-se que as atitudes em relação a eles sejam mais positivas entre os alunos das escolas secundárias onde o programa foi implementado, quando comparadas com as dos alunos das escolas onde isso não ocorreu.

Tabela 1

Dados Demográficos dos Estudantes Participantes por Província e Sexo

\begin{tabular}{|c|c|c|c|c|c|c|c|c|}
\hline \multirow{3}{*}{ Escolaridade } & \multicolumn{4}{|c|}{ Maputo } & \multicolumn{4}{|c|}{ Niassa } \\
\hline & \multicolumn{2}{|c|}{ Homens } & \multicolumn{2}{|c|}{ Mulheres } & \multicolumn{2}{|c|}{ Homens } & \multicolumn{2}{|c|}{ Mulheres } \\
\hline & $\mathrm{N}$ & $\%$ & $\mathrm{~N}$ & $\%$ & $\mathrm{~N}$ & $\%$ & $\mathrm{~N}$ & $\%$ \\
\hline $8^{\mathrm{a}}$ Classe & 21 & 40,4 & 26 & 26,8 & 34 & 28,3 & 26 & 32,5 \\
\hline $9^{a}$ Classe & 2 & 3,8 & 12 & 12,4 & 43 & 35,8 & 29 & 36,3 \\
\hline $10^{a}$ Classe & 29 & 55,8 & 59 & 60,8 & 43 & 35,8 & 25 & 31,3 \\
\hline \multicolumn{9}{|l|}{ Residência } \\
\hline Urbana & 31 & 56,4 & 61 & 67,0 & 37 & 33,0 & 24 & 32,9 \\
\hline Periurbana & 14 & 25,5 & 11 & 12,1 & 30 & 26,8 & 15 & 20,5 \\
\hline Rural & 10 & 18,2 & 19 & 20,9 & 45 & 40,2 & 34 & 46,6 \\
\hline \multicolumn{9}{|l|}{ Idade } \\
\hline $10-15$ & 13 & & 16 & & 31 & & 23 & \\
\hline $16-20$ & 26 & & 58 & & 34 & & 17 & \\
\hline $21-25$ & 7 & & 13 & & 4 & & - & \\
\hline $26-30$ & - & & 1 & & - & & - & \\
\hline
\end{tabular}

No que concerne à avaliação do impacto do programa Geração Biz, 252 estudantes (104 em Maputo e 148 em Niassa) estavam matriculados em escolas com acesso ao programa, enquanto os restantes 139 (70 em Maputo, 69 em Niassa) estavam matriculados em escolas nas quais o programa ainda não fora implementado.

\section{MÉTODO}

\section{Participantes}

O estudo contou com a participação de 391 estudantes de duas províncias de Moçambique, dos quais 174 de duas escolas de Maputo e 217 de duas escolas da província do Niassa. A média de idade dos alunos foi de 16,7 anos, com desvio-padrão de 2,6 anos. A análise dos dados permite identificar uma diferença significativa $\left(\mathrm{t}_{(241)}=4,56, \mathrm{p}<.001\right)$ nas idades dos estudantes das duas províncias, sendo os estudantes de Maputo (média $=17,4 ; \mathrm{dp}=2,7 ;$ mínimo $=13$ anos; máximo $=28$ anos) mais velhos do que os estudantes de Niassa (média $=15,9 ; \mathrm{dp}=2,3 ;$ mínimo $=10$ anos; máximo $=23$ anos). Pode ser identificada, na Tabela 1 , uma distribuição mais detalhadas das características demográficas dos participantes da pesquisa. 
A Escala de Atitudes Frente à aids, desenvolvida por Moriya, Gil e Hayashida (1994), tem por objetivo avaliar atitudes favoráveis e desfavoráveis frente à aids, bem como ajudar na avaliação de programas educativos relacionados ao HIV/aids. A escala no formato Likert contém 25 afirmações relativas à aids e foi levemente modificada na formulação das sentenças para se ajustar ao português corrente em Moçambique. Seis itens correspondem ao fator origens da doença e incluem assertivas como "A SIDA é uma punição de Deus perante o liberalismo do final do século XX" e "O uso excessivo de drogas intravenosas causou o aparecimento da SIDA". Um dos itens da escala foi excluído, por comprometer a consistência interna da medida, o que resultou em um alpha de .717. Onze itens correspondem à subescala conhecimentos sobre a aids, incluindo itens como "Casa de banho público é um local que pode transmitir a SIDA" e "A AIDS pode ser curada se detectada precocemente". Para fins de análise, quatro itens foram excluídos, resultando em um alpha de .628. Finalmente, oito sentenças correspondem ao fator avaliação do relacionamento com os soropositivos, o que inclui sentenças como "É um acto reprovável impedir a frequência de alunos em escolas, cujos pais são HIV positivos" e "Os portadores da SIDA devem ser tratados sem discriminação". Nesse caso, embora três itens da escala tenham sido excluídos, o valor do alpha permaneceu relativamente baixo (.508). Quanto mais alto o valor obtido pelo participante, mais ele demonstra conhecer as origens do HIV-aids, mais demonstra ter conhecimento sobre $\mathrm{o}$ assunto e avalia positivamente os portadores.

\section{Cuidados éticos}

O projeto foi submetido ao Comitê de Ética da Faculdade de Filosofia e Ciências Humanas e do Instituto de Psicologia da Universidade Federal da Bahia
(UFBA), sendo aprovado em reunião do referido comitê em 15 de dezembro de 2009.

\section{Procedimentos}

A aplicação dos instrumentos foi realizada coletivamente, de forma a não comprometer as rotinas estabelecidas nas escolas. Os diretores pedagógicos ajudaram a identificar os horários vagos. Os alunos responderam aos questionários na própria sala de aula. Embora a página inicial do caderno de instrumentos contemplasse a apresentação e as instruções de como proceder durante o preenchimento dos questionários, o pesquisador proporcionou uma explicação oral dos objetivos da pesquisa e informou como os instrumentos deveriam ser preenchidos. Ademais, em todas as aplicações, foram explicitados os objetivos da pesquisa, tendo sido enfatizada a preservação do anonimato.

\section{ANÁLISE E DISCUSSÃO DOS RESULTADOS}

O objetivo inicial do presente estudo foi submeter à prova a hipótese de que os estudantes secundários de Maputo apresentariam atitudes mais positivas em relação aos portadores do HIV-aids do que os estudantes de Niassa. Para testar essa hipótese, conduzimos três testes $t$ para a diferença entre as médias, um para cada uma das dimensões da Escala de Atitudes frente à aids. Os resultados, apresentados na Tabela 2, deixam claro que os estudantes de Maputo demonstraram ser mais precisos em relação às origens do HIV-aids $\left(\mathrm{t}_{(373,1)}=7,65, \mathrm{p}<.001\right)$, evidenciaram um maior grau de conhecimento $\left(\mathrm{t}_{(378,9)}=7,30, \mathrm{p}<.001\right)$ e adotaram um postura um pouco mais tolerante em relação aos portadores $\left(\mathrm{t}_{(377,7)}=2,66, \mathrm{p}<.05\right)$ do que os estudantes da cidade de Niassa.

Tabela 2

Média e Desvio-padrão das Dimensões da Escala de Atitudes Frente à aids, por Província

\begin{tabular}{lcc}
\multicolumn{1}{c}{ Dimensão } & \multicolumn{2}{c}{ Província } \\
& Maputo & Niassa \\
\hline Origem da doença & $4,03(0,64)$ & $3,34(1,01)$ \\
Conhecimento sobre a doença & $3,62(0,78)$ & $2,98(0,92)$ \\
Avaliação do portador & $2,60(0,83)$ & $2,35(0,96)$ \\
\hline
\end{tabular}

Esse quadro geral parece corroborar a nossa primeira hipótese de que os habitantes de uma região mais desenvolvida social e economicamente aparentam deter mais conhecimentos e adotar uma postura 
mais tolerante que os moradores da região menos desenvolvida. Esses resultados, entretanto, ganham novas cores a partir do momento em que conduzimos uma análise mais detalhada, considerando, por exemplo, o impacto do programa Geração Biz, o que nos leva diretamente à nossa segunda hipótese de trabalho.

Para avaliar a influência do programa Geração Biz nas duas províncias, que possuem características bem distintas em relação à avaliação atitudinal dos portadores do HIV-aids, conforme observamos anterior- mente, conduzimos uma análise da variância fatorial para cada uma das dimensões da Escala de Atitudes frente à aids, tomando como variáveis independentes a província de residência do estudante (Maputo versus Niassa) e o fato de estudar em uma escola na qual o programa Geração Biz foi ou não implementado. Ainda que as diferenças nas médias em cada uma das dimensões da escala possam ser identificadas na Tabela 3, apresentaremos e discutiremos, em separado, os resultados da ANOVA para cada uma delas.

\section{Tabela 3}

Diferenças nas Atitudes Sobre o HIV-aids Por Província e Implementação do Programa Geração Biz

\begin{tabular}{lcccc}
\hline \multicolumn{1}{c}{ Implementou Programa } & \multicolumn{2}{c}{ Maputo } & \multicolumn{2}{c}{ Niassa } \\
& Sim & Não & Sim & Não \\
\hline Dimensões na EAFAIDS & Média (DP) & Média (DP) & Média (DP) & Média (DP) \\
Origens da aids & $4,12(0,67)$ & $3,81(0,79)$ & $3,18(0,88)$ & $3,68(1,20)$ \\
Conhecimento sobre a aids & $3,69(0,76)$ & $3,51(0,80)$ & $2,85(0,82)$ & $3,26(1,07)$ \\
Relações com os soropositivos & $2,87(0,79)$ & $2,48(0,87)$ & $2,58(0,90)$ & $1,87(0,92)$ \\
\hline
\end{tabular}

\section{Origens da aids}

Conforme pode ser observado na Tabela 2, os estudantes de Maputo apresentaram escores significativamente mais altos do que os de Niassa nessa dimensão da escala. Esse efeito principal foi identificado pela ANOVA $\left(\mathrm{F}_{(1,381)}=35,34, \mathrm{p}<.01\right)$, o que corrobora a hipótese anterior. No entanto, outro efeito principal submetido à análise, o da influência positiva do programa Geração Biz, não pode ser constatado $\left(\mathrm{F}_{(1,381)}=0,51, \mathrm{p}=\mathrm{ns}\right)$.

O mais importante, no entanto, é que foi identificada uma interação entre a província e a implementação do programa Geração $\operatorname{Biz}\left(\mathrm{F}_{(1,381)}=20,67, \mathrm{p}<.01\right)$. As características dessa interação podem ser identificadas pela inspeção da Figura 1 .

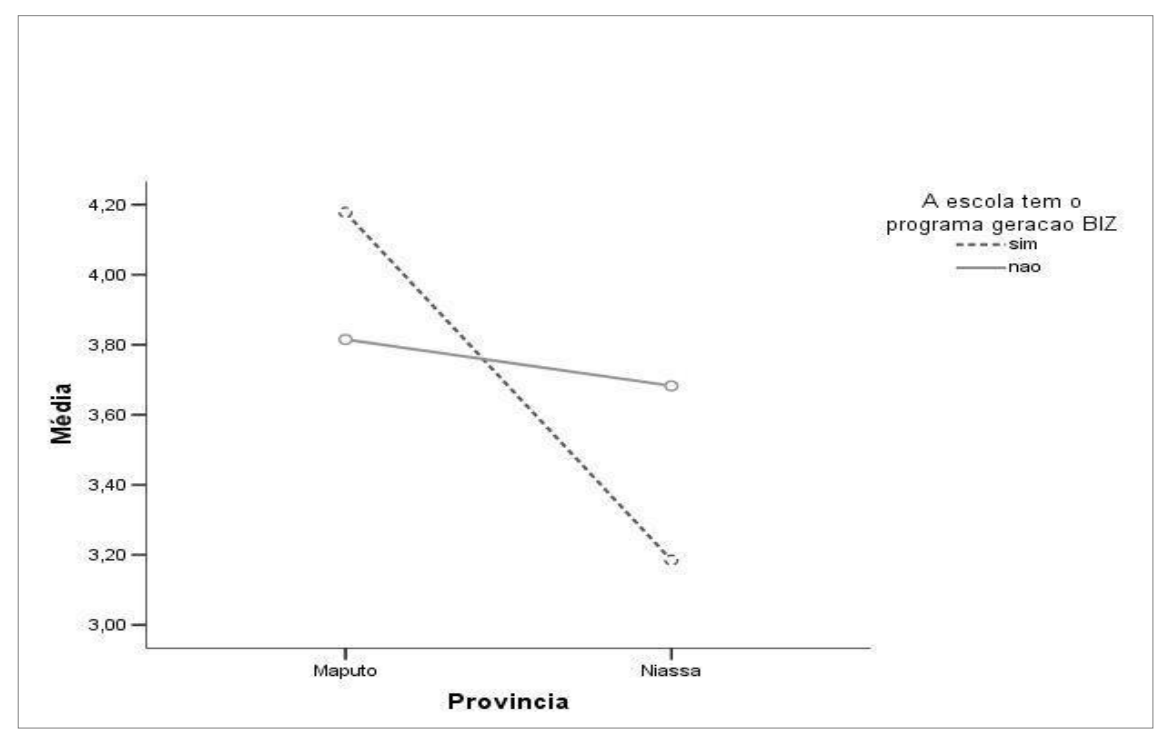

Figura 1. Médias do grau de conhecimento sobre HIV-aids. 


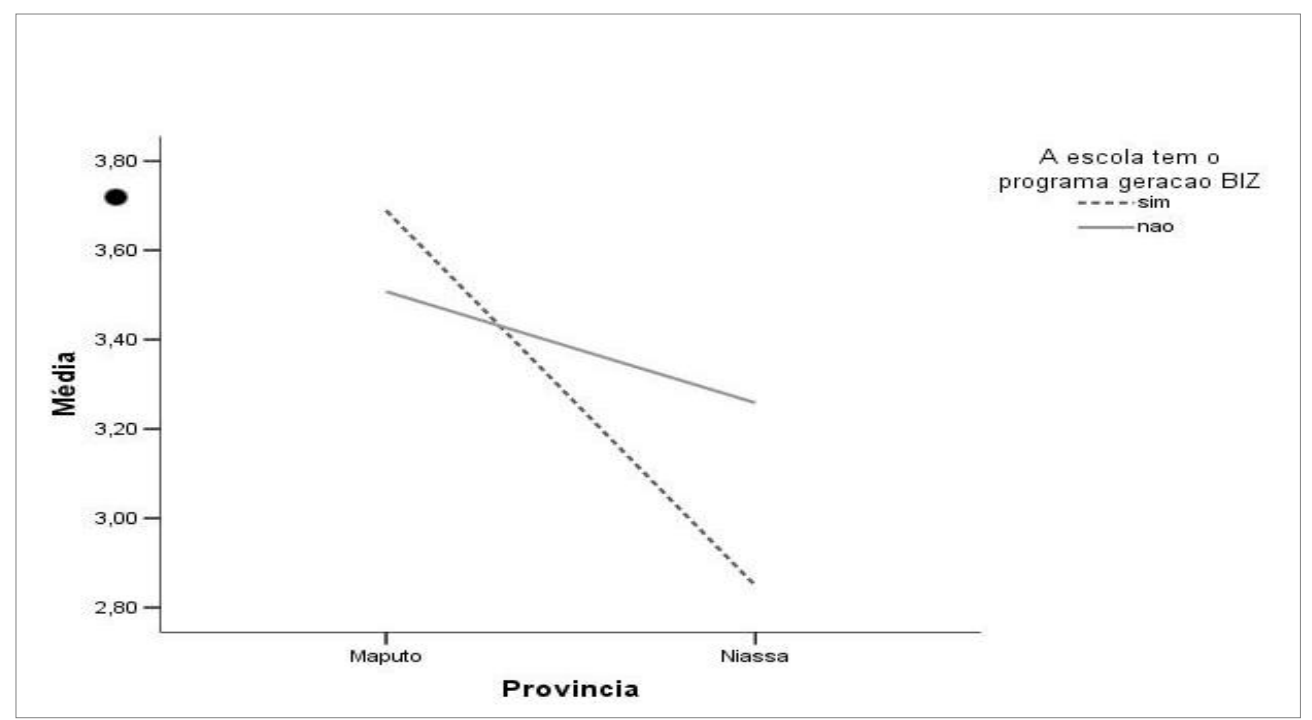

Figura 2. Médias das atitudes em relação aos portadores do HIV-aids.

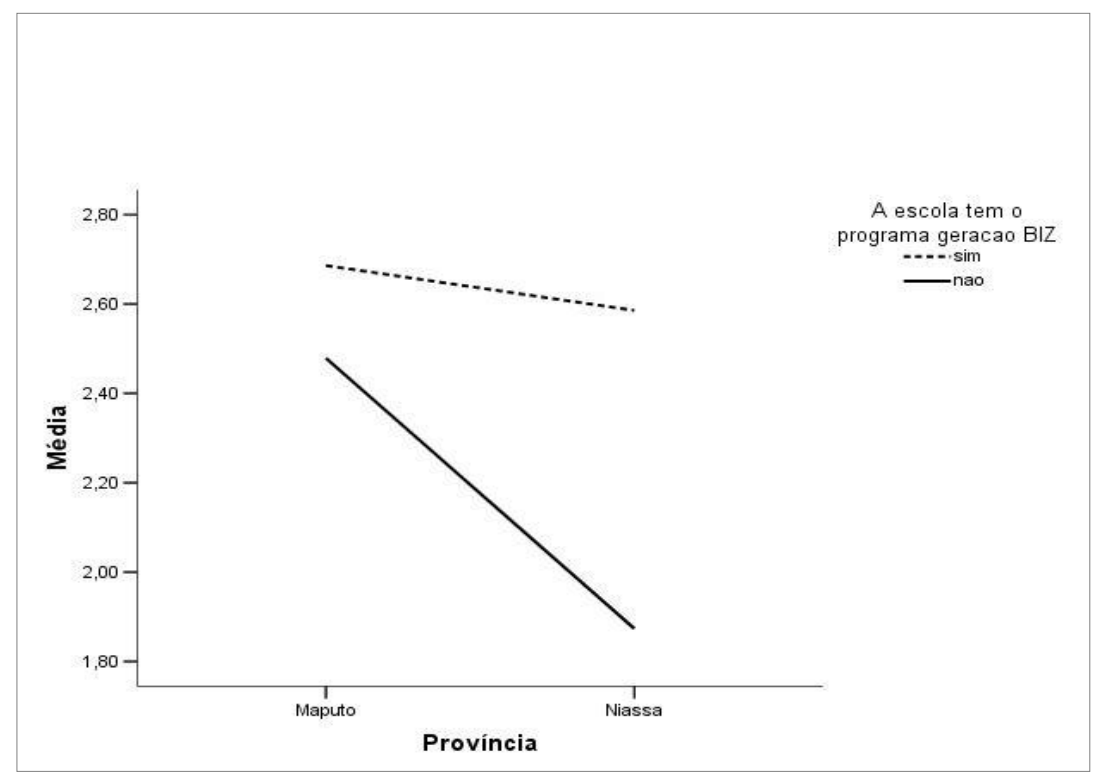

Figura 3. Medias por província e implementação do programa geração Biz.

Essa interação relativiza os resultados dos dois efeitos principais, ou seja, permite-nos considerar que essa aparente diferença na identificação das origens da aids por província reflete muito mais o efeito dos alunos da província de Niassa que frequentam escolas não participantes do programa Geração Biz e, em certa medida, o impacto dos alunos de Maputo, que frequentam escolas nas quais o programa foi implementado. Em relação ao impacto do programa Geração Biz, identifica-se claramente que ele produz resultados contraditórios, pois, se, na província de Niassa, foi o contrário do que se esperava - os alunos que dele participam apresentaram escores menos elevados do que os que frequentam escolas nas quais ele foi implementado, os resultados em Maputo evidenciam um efeito bastante positivo do programa, uma vez que os escores dos estudantes das escolas que dele participam foram significativamente mais elevados do que os obtidos pelos estudantes que frequentam as escolas não participantes do programa. 


\section{Conhecimentos sobre a aids}

Os estudantes de Maputo apresentaram escores significativamente mais altos na escala de conhecimento sobre a aids do que os de Niassa, um efeito principal, uma vez mais corroborado pela ANOVA $\left(F_{(1,381)}=35,44, p<.001\right)$. Novamente, o efeito isolado do programa Geração Biz não pôde ser constatado $\left(\mathrm{F}_{(1,381)}=1,552, \mathrm{p}=\mathrm{ns}\right)$.

Identificamos, uma vez mais, uma interação entre a província e a implementação do programa Geração $\operatorname{Biz}\left(\mathrm{F}_{(1,381)}=10,44, \mathrm{p}<.001\right)$, resultado facilmente identificado mediante a análise da Figura 2. O padrão da interação é relativamente semelhante ao identificado no caso da origem da aids. Uma vez mais, parece claro que as diferenças nos resultados relativos ao conhecimento da aids entre as diferentes províncias é uma consequência do menor conhecimento apresentado pelos alunos de Niassa que frequentam escolas participantes do programa Geração Biz. O impacto do programa Geração Biz não parece ser tão marcante no caso de Maputo, embora possamos identificar escores mais elevados entre os alunos das escolas que implementaram o programa. Os resultados parecem demonstrar que o impacto do programa nos estudantes das escolas de Niassa requer uma melhor avaliação, pois aqueles que frequentam as escolas nos quais ele foi implementado apresentaram uma clara redução no nível de conhecimento a respeito do assunto, quando comparados com os alunos das escolas nas quais não se implementou o programa.

\section{Relação com os soropositivos}

Essa é a única dimensão na qual o efeito principal do programa Geração Biz se manifestou com clareza e de acordo com a direção postulada na nossa segunda hipótese de trabalho $\left(\mathrm{F}_{(1,380)}=14,15\right.$, p.01), ou seja, de forma independente da província, os alunos que frequentam as escolas que implementaram o programa apresentam uma postura menos intolerante em relação aos portadores do que os que frequentam escolas nas quais o programa não foi implementado. Uma vez mais, pudemos identificar o efeito principal da província, o que evidencia que os estudantes de Maputo demonstraram uma menor intolerância em relação aos portadores do HIV-aids do que os de Niassa.

Mais uma vez, também pudemos identificar a interação entre as duas variáveis $\left(\mathrm{F}_{(1,380)=} 7,24, \mathrm{p}<.05\right)$, tal como se observa na Figura 3. Neste caso, ficou claro que as médias dos alunos de Maputo e Niassa que frequentam as escolas que implementaram o programa Geração Biz foram bastante próximas, ainda que um pouco abaixo do ponto de corte da escala. Em contrapartida, no caso específico dos estudantes de Niassa que frequentam escolas não participantes do programa, nota-se claramente que as médias são bem mais baixas do que em todas as outras condições, o que pode ser creditado a um impacto positivo do programa Geração Biz, no sentido de ampliar consideravelmente o grau de tolerância.

É importante salientar, no entanto, que os todos os escores, nessa dimensão da escala, são relativamente baixos e, conforme se observa na Tabela 3 , em nenhum caso se aproximam do ponto médio da escala. Ou seja, ao contrário dos resultados relativos às duas dimensões anteriormente discutidas, origens e conhecimento, os resultados benéficos do programa se manifestaram igualmente nas duas províncias, ainda que esse resultado possa ser considerado mais significativo na província de Niassa.

\section{DISCUSSÃO}

Iniciamos o presente artigo assinalando que o impacto da aids é diferenciado e as suas manifestações podem variar de país a país, a depender do nível de desenvolvimento social, econômico e cultural. Para avaliar se essa premissa global poderia ser localmente aplicada, submetemos a teste a hipótese de que os estudantes da cidade de Maputo, a capital de Moçambique, teriam conhecimentos mais precisos sobre o HIV-aids e apresentariam atitudes mais positivas sobre os portadores da doença do que os habitantes de Niassa, uma região predominante rural e menos desenvolvida do país.

Considerada isoladamente, a hipótese foi corroborada pelos dados. A oferta de informações, sobretudo no que concerne ao acesso aos meios de comunicação de massas, uma maior taxa de urbanização, bem como a presença, de forma mais acentuada, de uma infraestrutura de serviços, podem contribuir para explicar tais diferenças, no que concerne ao conhecimento e, consequentemente, às atitudes dos habitantes das duas províncias em relação aos portadores do HIV-aids.

Os resultados evidenciados pela testagem da segunda hipótese do nosso estudo nos colocaram frente a um quadro bem mais complexo, permitindo-nos, inclusive, reavaliar os resultados obtidos na testagem 
da primeira hipótese. Ao partirmos da hipótese de que os estudantes das escolas que implementaram o programa Geração Biz apresentariam um resultado mais expressivo nas três dimensões da escala do que os alunos das escolas nas quais o programa não foi implementado, dávamos por suposto que a oferta de informações e as várias estratégias de ação adotadas no programa poderiam proporcionar benefícios significativos em relação ao conhecimento e uma maior sensibilização em relação aos portadores do HIV-aids. Isoladamente, os efeitos do programa foram identificados apenas no que concerne à dimensão relação com os portadores. Esse resultado pode nos levar a supor, por exemplo, que as atitudes podem se tornar mais positivas, mesmo que elas continuem a encontrar os seus fundamentos numa base de conhecimento admitidamente falsa.

O programa Geração Biz, por si, parece não fazer efeito no nível de conhecimento, como pode ser visto nas Figuras 1 e 2, ao mesmo tempo em que apresentou resultados na expressão das atitudes. $\mathrm{O}$ que poderia explicar esse aparente paradoxo? De acordo com o modelo probabilista de elaboração (Petty e Caciopo, 1986), poder-se-ia esperar que os estudantes fossem adotar as atitudes compatíveis com o programa Geração Biz. A adoção dessas atitudes, no entanto, seria uma função das diferenças individuais e dos fatores presentes na situação. Do ponto de vista do percebedor, ele deveria estar motivado a processar a informação de forma cuidadosa e a elaborar argumentos relevantes ao problema, ou seja, deveria ser capaz de produzir um pensamento relevante à mensagem. Dois fatores são decisivos na elaboração desse pensamento relevante: o envolvimento, que afeta diretamente à motivação para participar do programa, e a capacidade de evitar a distração, ou seja, a capacidade de refletir de forma consistente sobre as informações e se furtar à influência de outras fontes de informação, particularmente das crenças culturalmente enraizadas que dificultam o combate à aids. Se a fonte de influência for exclusivamente externa, particularmente as fontes de informação que exercem uma grande atração, sem que haja o envolvimento pessoal ou sem o processamento cuidadoso da informação, qualquer mudança ocorre de forma periférica, o que torna a mudança da atitude menos duradoura e menos resistente a argumentos contrários, gerando pouco impacto na probabilidade de impelir mudanças comportamentais na direção predita pelas atitudes. A ausência de uma rota central para a mudança das atitudes talvez possa explicar por que o grau de conhecimento sobre o HIVaids não foi influenciado pelo programa Geração Biz, ao mesmo tempo em que se observou uma mudança nas atitudes em relação ao portador.

\section{CONSIDERAÇÕES FINAIS}

Gostaríamos de finalizar o presente artigo assinalando a importância e o significado que programas como o Geração Biz possuem numa sociedade como a moçambicana. Os resultados aqui apresentados deixam claro que qualquer programa deve ser implementado à luz do contexto sociocultural no qual se insere, particularmente em um país como Moçambique, no qual se observa uma grande variedade nas práticas e nos costumes entre suas diversas regiões. Torna-se necessário avaliar os papéis sociais valorizados em cada meio social, bem como identificar quem desempenha esse papel, pois, presumivelmente, essas pessoas podem contribuir de forma significativa na credibilidade do conhecimento que se pretende transmitir aos estudantes e à comunidade em geral.

Uma das limitações do presente estudo é o fato de termos feito a pesquisa apenas em quatro escolas secundárias de duas províncias. Por isso, é urgente a condução de novos estudos mais abrangentes e que sejam capazes de incorporar e avaliar atitudes sobre o HIV-aids em outras regiões do país. Como a população estudada foi a de alunos das escolas secundárias, deixando de parte alunos do ensino primário, do segundo grau, e outros níveis de ensino, certamente o presente estudo deve ser completado com outros que assegurem uma avaliação cuidadosa do impacto da aids nas mais diversas esferas da sociedade.

\section{REFERÊNCIAS}

Aparecido, S. W, Buchala, C. M., Paiva, V., Oliveira, L. M R., Stall, R. \& Norman, H., (2002). Prevenção de doenças sexualmente transmissíveis e aids entre jogadores juniores. Revista de Saúde Publica, 36, 68-75.

Brazilian Ministry of Health. (2010). Response positive: The experience of Brazilian STD, Aids and Viral Hepatitis Department. Brazilian Ministry of Health: Brazilia.

Bukusula, J., Kikafunda, J. K. \& Whitehead, R. G. (2007) Food security status in households of people living with HIV/AIDS (PLWHA) in a Ugandan urban setting. British Journal of $\mathrm{Nu}$ trition, 98, 211-217.

Camargo, B. V., \& Botelho, L. J. (2007). Aids, sexualidade e atitudes de adolescentes sobre a proteção contra o HIV. Revista de Saúde Pública, 41, 61-68. Retirado em 04 de setembro de 
2009, de http://www.scielo.br/scielo.php?script=sci_arttext\& pid=S0034-

Camargo, B. V., Bárbara, A., \& Bertoldo, R. B. (2005). Um instrumento de medida da dimensão informática da representação social da aids. In Jornada Internacional e II Conferência Brasileira sobre Representações Sociais (Ed.), Textos Completos da IV Jornada Internacional e II Conferência Brasileira sobre Representações Sociais (p. 10). João Pessoa.

Conselho Nacional de Combate ao HIV-SIDA. (2010). Plano Estratégico Nacional de Resposta ao HIV e SIDA 2010-2014. Maputo, Moçambique: Conselho Nacional de Combate ao HIV-SIDA .

Donnelly, J. (2004). Programa anti-aids na África pede ajuda aos curandeiros. Retirado em 03 de setembro de 2009, de http://noticias.uol.com.br/midiaglobal/boston/2004/12/26/ult58 3u214.jhtm

Eagly, A., \& Chaiken, S. (1998). Attitude structure and function. In D. T. Gilbert, S. T. Fiske \& G. Lindzey (Eds.), The handbook of social psychology: Vol. 1 (pp. 269-322). New York: McGraw-Hill.

Faria, M. R. V. (2007). Crença no mundo justo, aids e câncer de pulmão: Orientação sexual e responsabilização individual (Dissertação de mestrado). Universidade Católica de Goiás, Goiânia. Retirado em 20 de novembro de 2010, de http://tede. biblioteca.ucg.br/tde_busca/arquivo.php?codArquivo=329

Fonseca, P. N., Gouveia, V. V., \& Gouveia, R. S. V. (2007). School attitudes scale: Factor validity and reliability. Psicologia Escolar e Educacional, 11, 285-297.

Garbin, C. A. S., Martins, R. J., Garbin, A. J. Í., Lima, D. C., \& Prieto, A. K. C. (2009). Percepção de pacientes HIV-positivo de um centro de referencia em relação ao tratamento de saúde. DST - Jornal Brasileiro de Doenças Sexualmente Transmissíveis, 21, 107-110.

Governo de Moçambique. (1983). Publicação Oficial da Republica Popular de Moçambique. I Série-Número 12. Quarta feira, 23 de Março. Maputo, Moçambique.

Granjeiro, A. Teixera, L. Bastos, F. I., \& Teixera, P. (2006). Sustentabilidade da política de acesso a medicamentos antiretrovirais no Brasil. Revista de Saúde Pública, 40, 60-69.

Instituto Nacional de Estatística. (1997). Estatísticas setoriais: Educação. Maputo, Moçambique. Retirado em 20 de Novembro de 2010, de http://www.ine.gov.mz/sectorias_dir/educacao 9804/

Kruger, H. (1986). Introdução à psicologia social. São Paulo: EPU.
Leyens, J. P., \& Yzerbyt, V. (2004). Psicologia social (B. Lalardy, Trad.). Lisboa: Edições 70.

Mason, C. (2007). HIV-AIDS: Western failure and Ugandian success. Retirado em 20 de novembro de 2010, de http:// www.pop.org/content/hivaids-western-failure-and-ugandansuccess-758

Matsinhe, C. (2006). Tabula rasa: Dinâmica da resposta moçambicana ao HIV/SIDA. Maputo: Texto Editores.

Ministerio da Educação e Cultura. (2010). O programa Geração Biz. Maputo, Moçambique: Ministerio da Educação e Cultura.

Ministério da Saúde. (2005). Resposta positiva: Experiência do Programa Brasileiro de aids. Brasília: Ministério da Saúde.

Ministério da Saúde. (2010). Inquérito nacional de prevalência, riscos comportamentais e informação sobre o HIV e SIDA em Moçambique. Maputo, Moçambique: Ministério da Saúde.

Moriya, T. M., Elucir, G., \& Hayashida, M. (1994). Escalas de atitudes frente a aids: Uma análise psicométrica. Revista Latino-Americana de Enfermagem, 2, 37-53.

Organização das Nações Unidas para o Combate da Aids. (2008). África subsahariana: Situación de la epidemia de SIDA: Resumen regional. Genebra: ONU.

Pereira, M. E. (2002). Psicologia social dos estereótipos. São Paulo: EPU.

Petty, R. E., \& Cacioppo, J. T. (1986) Communication and persuasion: Central and peripheral routes to attitude change. New York: Springer-Verlag.

Programa das Nações Unidas para o Desenvolvimento. (2008). People living with HIV, 15-49 years old, percentage. Genebra: ONU. Retirado em 20 de novembro de 2010, de http://www. pnud.org.br/odm/objetivo_6/

Programa das Nações Unidas para o Desenvolvimento. (2010). Objetivos do desenvolvimento do milênio. Genebra: ONU. Retirado em 17 de novembro de 2010, de http://www.pnud.org.br/ odm/objetivo_6/

Rodrigues, A. (2007). Psicologia social para principiantes. Petrópolis: Vozes. 